\title{
LA VIOLENCIA EN LA ESPAÑA REPUBLICANA
}

\author{
Antonio Nadal \\ Universidad de Málaga
}

\section{HACIA UNA TEORIA DE LA VIOLENCIA}

Resulta difícil para el pueblo español asumir que pudo existir una violencia represiva en el campo de la República. Sin reparar las dramáticas e históricas afrentas, quienes andaban oculto el rostro, baja la cabeza en pueblos o guardando por miedo e incluso "vergüenza" familiar su pasado republicano, no se reconocen en hechos o acontecimientos deshonrosos para la República. Su "parte" de verdad no sólo sigue intacta, sino que frente al olvido han agrandado la razón. Esta España ha recuperado la libertad pero nadie les ha devuelto honestidad y dignidad. La transición, "modélica", al sistema democrático, ha posibilitado, entre otras ausencias, clamorosas marginaciones ya irrecuperables. No todos, ni mucho menos, somos responsables.

La violencia es un concepto ambiguo, ambivalente y contradictorio. La violencia consiste en "recurrir a la fuerza", "tomar medidas violentas", "apelar a la fuerza" (there was violence), "morir violentamente" (to die by violence), hasta "agredir". "robar", "odiar".

Así pues, no es extraño que en un examen superficial, a las publicaciones de ciencias sociales o jurídicas, descubramos la violencia vivida, violencia visualizada, violencia sagrada, violencia de los medios. violencia simbólica, violencia cotidiana, violencia de Estado, violencia política. violencia social, violencia económica.... y todas ellas con objetos precisos de conocimiento ${ }^{1}$.

La violencia es la expresión externa de un conflicto, cuyo grado de intensidad, rompe los márgenes de las tensiones "institucionales", y adquiere un límite especifico

\footnotetext{
'Véase, Imbert, G.: Los escenarios de la violencia. Barcelona, 1992. Michaud, I.: Violente et politique, Gallimard, 1978. Pross, H.: La violencia en los simbolos sociales. 1983. Cisnes, J.C.: Fiestera de la violente. Roberto Laffont. 1981. Loewenstein. B.: "Scheme of the Civil society and violente". Sociologicky Casopis. Vol 27. 1991. Pp. 133-143. Hunter, J.A. et al.: "Intergroup violente and Intergroup atributions. British Journal of social Psychology. Vol. 30. 1991. Pp. 261-266. Riches, D.: “Agression, war, violente-space /time and Paradism". Man, 1991, Pp. 281-298. Brush, L.D., Schippers,M.: “Intimate violente. A study of injustice". Gender and Society. 1991. Vol. 5. Pp. 269-272. Benjanin. W.: "Contribution to the criticism of violente". Sociologicky Casopis. 1990. Vol. 26. Pp 543-551. Herrero, J.L.: ¿Qué es la violencia? Madrid, 1971. Ruperez Rubio, I.: "Las motivaciones de la violencia”. Ciuadernos para el Diálogo. № 19. 1965. Pág. 36. Storr, A.: La agresividad humana. Madrid, 1970. Freud, S.: El malestar en la cultura. Madrid, 1966. Pp. 102-103. Comaton, M.: Violences et societe. Paris, 1969. Remond, R.: La violencia. Bilhau, 1969. Massun. V.: La libertad y la violencia. Buenos Aires, 1968. Ellacurria, 1.: "Violencia y cruz", en Qué aporla el cristianismo al hombre de hoy. Bilbao, 1969. Fanon. F.: Los condenados de la tierra. Méjico, 1963. Michaud, I.: Violencia y política. Paris, 1980.
} 
de acuerdo con las características del sistema ${ }^{2}$.

En la perspectiva positiva de Comte, la violencia se ajustaba al nivel de inmadurez de una sociedad ${ }^{3}$. Sin embargo las más avanzadas tesis sobre la violencia están imbricadas con la teoría del Estado: la primacía del orden y el Estado (Hobbes, Hegel, después Weber), o por el contrario, las actuales relavizaciones del Estado en favor de una sociedad plural con niveles altos de organización (desde Locke al marxismo).

La contradictoria historia del siglo $\mathrm{XX}$ ha encaminado a historiadores, politólogos y científicos sociales a centrar el conflicto en las divergencias de intereses y "entender la idea del consenso tan sólo como encubrimiento de las relaciones fácticas del poder”, en un mundo polarizado por las desigualdades sociales.

Dowse y Hughes, atendiendo a la naturaleza y proporción de la violencia, caracterizan a ésta: A) desorden; B) violencia conspirativa; C) guerra interna ${ }^{5}$. La tesis weberiana se muestra incapaz de explicar la casuística del conflicto agudo y el papel del Estado: "Hablaríamos de guerra civil cuando las partes de un conflicto se muestran dispuestas a ese conflicto por medios violentos y con ello niegan lo que constituye la esencia de la definición del Estado, a saber, su monopolio de los medios legítimos de coerción física" ${ }^{* 6}$. ¿Sería aceptable esta tesis para la Convención Francesa o la II República española?

Por otra parte, la violencia está íntimamente ligada al concepto teórico de Revolución, (en que aquella podría actuar como medio), a los procesos transformadores en la Europa moderna y, de especial manera, a la Revolución francesa ${ }^{7}$. Desde aquí toda una corriente historiográfica interpreta que la relación entre libertad y revolución (con sus métodos "violentos"), son harto problemáticos. Los grandes principios de las democracias modernas occidentales se contrapondrían, a las etapas revolucionarias, paréntesis o epifenómenos de la historia europea. Pero no es todo tan fácil.

${ }^{2}$ R. Dahrendorf.: Sociedad y libertad. Madrid, 1966. E. Dowse y J.A. Hughes.: Sociología politica. Madrid, 1979.

${ }^{3}$ M.A. Weinstein.: Las ideologías de la violencia. Madrid, 1976.

${ }^{4}$ K.V. Beyme.: Teorias políticas contemporáneas. Madrid, 1974.

5 Dowsen y Hughes.: Sociología Política. Madrid, 1979.1) Desorden: "violencia relativamente espontánea y desorganizada con amplio apoyo y participación populares". Huelga, disturbios. Es la reacción a privaciones agudas de las clases populares. 2) Violencia conspirativa: "es la ejercida normalmente de manera muy organizada por segmentos de la élite como el ejército y la burocracia". Golpes de Estado, asesinatos, por pérdidas de privilegio. 3) Guerra intema: "alto nivel de organización y por lo menos con la aprobación táctica de amplios sectores de la población. Se incluye en esta forma de violencia el terrorismo en gran escala, las guerras civiles y las revoluciones.

${ }^{6}$ Rex, J.: El conflicto social. Madrid, 1985.

${ }^{7}$ Los conceptos y análisis de revolución desde perspectivas diferentes: Hobsbawn, E.J.: "La Revolución", en Roy Porter y Milukas. T. (eds).: La Revolución en la Historia. Barcelona, 1990. Kossok, M.: "El ciclo de las revoluciones burguesas españolas en el siglo XIX. Problemas de investigación e interpretación a la luz del método comparativo", en La Revolución burguesa en España (ed. e introd. de A. Gil Novales). Madrid, 1985. Brinton, A.: Anatomía de las revoluciones. Madrid, 1962. Bailey, V.: "Street violente in the 19th. century". Eronomic History Review. 1991. vol. 44. Pp. 544-554. 
Es aconsejable a los estudiosos de las rebeliones, revoluciones o violencia (conceptos que "conviven" sin matizaciones en científicos sociales), desenmascarar los mitos que las esconden para reducirla a su propio significado ${ }^{8}$. Reducción "cultural", que debe extenderse a tantos conceptos politológicos, manejados con frívola frecuencia e indeterminación. No obstante el término "violencia" se revela desde la década de los 70 , profunda e inevitablemente, unido al de "terrorismo" y "guerra", de violencia política a violencia criminal, en un preocupante confusionismo. La "violencia" ha dejado de ser definitivamente un "rasgo", al menos, de oposición a las sociedades injustas y desiguales", incluso para los objetivos e intereses históricos de la burguesía.

Pese a la "contradicción" libertad-revolución, los movimientos, en que aparece la violencia, como instrumento político, ocupan un lugar central en la historiografía moderna. La violencia, proporciona a los cambios históricos la posibilidad de una interpretación a corto y largo plazo ${ }^{10}$. Los mecanismos de protesta en la transición al capitalismo están documentados como formas de participación política. Para Thompson y Rudé las revueltas populares componen una defensa de la "economía moral", de aprovisionamiento tradicional contra la "nueva economía" de mercado libre, formas de ordenar la vida de acuerdo con la justicia social" ${ }^{11}$.

\footnotetext{
${ }^{8}$ P. Bordieu, J.C. Chamboredon y J.C. Passeron.: Le Metier de Sociologie. Paris, 1973.

9 Publicaciones, en este caso es una simple enumeración insignificante, como Ireland's terrorist trauma. (Alan O'Day Yohan Alexander (eds). Abril, 1978-. Mas ilustrativo es Terrorism, Ideology and Revolution. (Mod O'Sullivan (eds), que traza ni mas ni menos que el origen del "terrorismo desde la Revolución Francesa, su extensión por Europa hasta el Tercer Mundo". Así pues, aparecen juntos el terror francés, el terror nazi, el terror irlandés, el terror islámico, la violencia en Turquía... (Harveter. Wheats Hear). Political violente and terror. (Peter Merkly, Califomia, 1986). Se estudian ejemplos de violencia $\mathrm{y}$ terrorismo en sus hechos y motivaciones: "As acts of terrorism and political violente proliferate in the world,...". En un terreno más teórico, la violencia se enmarcaría en el mismo nacimiento del marxismo, Baber, Z.: "The violente of Abstraction in the analitic foundations of Historical Materialism" Journal of Contemporary Asia. 1991. vol. 21. pp. 246-252.

${ }^{10}$ Hilton L. Root.: Politiques frumentaires et violente colective en I'Europe de XVIII siecle. Annales Esc. Jan-Feb, $n^{9}$ 1. Pp. 167-189. Charles Tilly, en "Collective violente in European perspective", en H.D. Graham y T.R. Gurr (eds).: The history of violente in America. New York, 1969. Dickson D. Bruce, Jr.: Violente and culture in the Antebellum South. Texas, 1979. Chalmers Johnson.: Revolution and the social system. Stranford, 1964. Del mismo autor.: Revolutionary Change. Boston, 1966. J.H. Elliot.: "Revolution and continuity in early Modem History", Past and Present, $\mathrm{n}^{\circ} 42,1969$. J.H. Elliot y otros.: Revoluciones y Rebeliones en la Europa Moderna. Madrid, 1972. Glazebrooke, S.G.: Justice in transition: crime, criminals and criminal justice in Revolutionary Rouen, 1790-1800. Oxford, 1988. Maltby, H.R.O.: Crime and local comunity in France: The Departmen of the Drome, 1770-1820. Oxford, 1980. Blok A.: The mafia of a sicilian village, 1860-1960. A study of violent peasants entrepeneurs. Oxford, 1988. ()'Kane. R.: The Revolutionay Reign of Terror: the role of violente in Political Change. Oxford. 1980. Ieon Friedman (eds).: Violente in América. 16 vols. Chelsea, 1985. Veiseer, R. M.: Crime and Punishment in Early Modern Europe. Harvester, 1989.

$"$ Rude, G.: The Crowd in History: a Study of Popular Disturbances in France and England, 1730-1848. New York, Wiley and Sons, 1964. E.P. Thompson.: "The Moral Economy of the English Crowd in the Eighteenth Century". Past and Present, 50. 1971. Siguiendo a Rudé, Ch. Tilly.: The Contentious French. Cambridge, 1986. I.. Tilly.: "Food Entitlement, Famine and Conflict", en Roberto I. Rotberg et Theodore K. Rapp, eds. Hunger and History: the Impact of Changing Food Production and
} 
D. Roche se aproxima a la cuestión desde una doble perspectiva: 1) En la primera son discutidas las formas políticas violentas contenidas en las Luces. Especialmente en Rousseau y sus émulos. como fuentes del radicalismo revolucionario y el jacobinismo terrorista. El problema es saber cómo se pasa del proyecto politico de las Luces (Voltaire, Condorcet, Rousseau), a los excesos del Terror. La respuesta de Agulhon es conocida, la violencia seria menos el resultado de un hiper racionalismo programado inherente a la ideología jacobina que el resultado de quienes desean sostener la libertad y el poder.

2) El segundo gran hecho corresponde al historiador de las mentalidades: el miedo, la reacción defensiva, la violencia punitiva constituye una de las claves de la comprensión de la situación revolucionaria, psicología de las masas, el estudio de los comportamientos de los sansculottes, son otros medios para entender la instauración de la violencia ${ }^{12}$.

Esta reflexión abre vías de interés para nuestro trabajo: 1) ¿Contenían planteamientos teóricos definidos de violencia una fracción de los partidos o sindicatos en la España republicana?. Si es así, ¿qué relación hubo entre teoría y práctica, o fue la firmeza de defender un sistema. presionados, además por la contrarrevolución?. El tema, sin duda, es de gran envergadura y sugiere una importante reconsideración de muchas generalizaciones.

\section{LA VIOLENCIA REPUBLICANA}

La violencia en España, ha desvencijado los márgenes del Estado, ¿revolución?. con ruptura del accidental "consenso", violencia que opera como instrumento político de gran magnitud. Perfil inteligible de la historia de España que patentiza la peculiaridad nacional, frente a Hobsbawn que relativiza el fenómeno de la violencia en los procesos revolucionarios. Obvio, como queda dicho, conscientemente. el azorado razonamiento que surgiría al aplicar los esquemas weberianos, ¿se imaginan a toda la pléyade de "estadistas" sugiriendo, solamente, que la República. Estado legítimo, monopolizador de la fuerza y el poder, debía haber impuesto con toda

Consumption Patterns on Society. Cambridge, 1985. and Journal of Interdisciplinary History, 14, 1983. pp. 333-349. Tambien en, "The l'ood Riot as a Form of Political Conflict in France", Journal of Interdisciplinary History. 2, 1971. Pp. 23-57. J. Walter y K. Wrightson, "Death and the Social Order in Early Modern England". en P. Slack. ed.. Rebellion. Popular Protest and the Social Order in Early Modern England. Cambridge. 1984. J. Stevenson.. "The Moral Economy of the English Crowd", en A. Fletcher y J. Stevenson, eds.: Order and Disorder in Early Modern England. Cambridge. 1985. J. Bohstedt.: Riots and Community Politics in England and Wales, 1790.1810. Cambridge. 1983.

${ }^{12}$ Roche, D.:" l.a violente vue den Bas. Reflexions sur les moyens de la politique en periode Revolutionnaire". Annales. Esc. Jan-1Feb 1989, $\mathrm{n}^{\circ}$ I. Pp. 47-65. La bibliografía que conduce desde el "terror jacobino" al "Gulag", entre crros.: P. Chaunu.: L'historien dans tous ses états. Paris, 1984. R. Secher.: Le genocide franco-français, la Vendeé-Vengé. Paris, 1986. F. Bluche.: Septembre 1792 les logiques d'un massacre. Paris. 1986. I: Lenbrun.: "La guerre de Vendée massacre ou génocide", L'Fiestera, mars 1985, Pp. 93-99. C.I anglois.: "La Révolution malade de la Vendée", XX' siecle. 1987. Pp. 63-78... 
dureza el ejercicio de coerción física contra los sublevados?.

Es de inevitable referencia acudir a Gramsci. El Estado sería "hegemonía acorazada de coacción", es decir. sociedad política más sociedad civil. En los momentos de crisis se plantearía la separación entre sociedad civil y sociedad política: la clase dominante no consigue ya ejercer su hegemonía aunque continúa ejerciendo su "dictadura" y la clase que constituye su antagonista directa y reivindica el poder ejerce ya su hegemonía, pero no la "dictadura" (no consigue crear Estado). Esta interesante visión es aplicable a toda la lucha social en el Estado gestionado por la República pero dominado por las clases del pasado.

\subsection{Contra la "ideología" en el estudio de la violencia republicana}

El pueblo español debe conocer desde la precisión histórica, la objetividad y una disciplinada metodología los hechos violentos que se sucedieron en la zona republicana para aislarlos de "la propaganda fascista" y la "apocalipsis" de la Iglesia Católica ${ }^{13}$. No pueden plantearse posiciones defensivas. Por ello, aclaro, prescindiré al tratar la violencia republicana de la procelosa y abundantísima adjetivización que historiadores, pasados y presentes, enfatizan: sanguinaria, feroz, criminal, obscura, traumática, turbia, penosa, hipócrita, escabrosa, lacerante, ¿por qué?. Pareciera que escribir sobre la represión republicana fuese un "via crucis" en que conforme se avanza, deban aparecer estaciones, adjetivos, que justifiquen a los dirigentes republicanos e incluso al historiador. A los primeros fue la impotencia, el dolor y la claridad del error..., y son las palabras actos sinceros. No es admisible en quienes oficiamos la tarea. Cada adjetivo se convierte en sustantivo, enrevesadas aclaraciones que nadie ha pedido, hipótesis previamente configuradas... Un temor que parece querer reparar una hipotética condena. La represión republicana fue una realidad.Velada "violencia", en planteamientos teóricos, supeditada a la improvisación defensiva: revolución de 1934, Plenos de la FAI por 1933 y $1936^{14}$. Cosa distinta fue la

\footnotetext{
${ }^{13} \mathrm{Ha}$ sido imposible, por razones de espacio, presentar un estudio detallado de las fuentes para el estudio de la represión republicana, así como para tratar de determinar ciertos conceptos cuya calificación seria imprescindible. Fuentes: Causa General. Archivos de Prisiones de Partido, Provinciales, Funerarias. Historia Oral, expedientes levantamiento de cadáveres en la Audiencia Provincial, Libros de Cementerios, Hospitales, Registros civiles... Sobre éste último, ver, Nadal. A.: "Los Registros Civiles, centro del debate metodológico para el estudio de la represión". Congreso Asociación Historia Contemporánea. Salamanca. 1992. Otros hechos, como las "sacas" de las prisiones, un estudio profundo del término "espontaneismo". tendremos oportunidad de desarrollarlo en or ro lugar.

${ }^{14}$ Resulta "evidente", en cualquier caso, para algunos historiadores relacionar con "violencia" los acontecimientos revolucionarios pasados y presentes: Singh, R.: "Violente in the Leninist Revolution". Economic and Political Weekly. 1990, Vol.2 5. Pp. 28-43. Rigby, V.: "Coping with the Epidemic of violente. The struggle over health-care in the Intifade". Journal of Palestine Studies. 1991. vol. 20. Pp. 86-98. Gilmore, D.: "Basque violente. Metaphor and Sacrament". American Ethnologist. 1991. Vol. 18. Pp. 611-612. Reynolds. P.: "People and violente in South Africa". Social Dinamics. A Jounal of the Centre for African Studies. 1991, Vol. 17. Pp. 134-135. Obershall, A.: "Policies of chaos. The organizational causes of violente in China cultural-revolution". Contemporary Sociology. An international Journal of Reviews. 1991. Vol. 20. Pp. 207-208. La violencia, defensiva y ofensiva, como tesis en los partidos y sindicatos de la izquierda, es una cuestión de máximo interés que debe ser investigada.
} 
incapacidad táctica y la ruptura de pasiones que tantos responsables acreditó (Azaña habla de algún intelectual de la "Tercera España"), que autocalificada de "revolucionaria", se ejerció como respuesta improvisada, desorganizada y dividida (me resisto a emplear el término espontáneo), como lucha épica o supervivencia, de un pueblo valeroso, que veía o intuía el final de una corta experiencia. Y recorrio, semejante a un río de muertes, ejecuciones, paseos, venganzas, juicios regulares..., el verano de 1936 (con excepciones, Madrid, en noviembre).

No sé si "moralmente" podría decirse que la violencia republicana fue o hubiera sido más breve que la franquista (40 años de Régimen). Sin duda, sí... Es coincidencia relativamente común, reputar que, superados los seis primeros meses de guerra, la represión fue contenida por el gobierno. Sospecho más compleja la situación. En estos meses, rápidas y frenéticas acciones violentas, cubrieron básicamente los "objetivos" (no especialmente diáfanos, además de la muerte física), se fueron imponiendo los grupos y elementos equilibrados, se priorizó en temas militares y actuó el gobierno de Largo Caballero. La "burguesía", el "clero" y otros enemigos habían sido en número considerable ejecutados, o se les mantenía en prisión (eso sí, a cubierto de las primitivas "sacas"). No había más. El resto de la sociedad ya no representaba económica o socialmente a las clases dominantes, a quienes se redujo en retaguardia, aunque participaran de sus creencias religiosas o culturales. Por otra parte, no creo que los Tribunales Populares en parte de la zona republicana, fuesen el parapeto de la Ley, los garantes de que la "justicia" regular, ¿qué era la justicia?, funcionase en la España Republicana. En los tribunales de hecho entraron los mismos miembros de los anteriores Comités (de la Justicia "revolucionaria"). Los que se hallaban en la cárcel tras los meses citados, salvo excepciones, eran derechistas de segunda fila, que sólo alguna venganza, bombardeo o denuncia podían posibilitar su salida frente al Tribunal Popular. La gran labor de los Tribunales Populares fue aplicar un justicia regular sobre personajes de inferior relevancia, salvo en las regiones donde la guerra ocupó los tres años. Tampoco debe olvidarse que de acuerdo con las autoridades gubernamentales, los expedientes se iban "paralizando", ante las protestas de los representantes políticos y sindicales que desconocían las técnicas judiciales ${ }^{15}$.

\footnotetext{
is Sobre Tribunales Populares y Justicia en general: Justicia en Guerra. Jornadas sobre la Administración de Justicia durante la Guerra Civil: instituciones y fuentes documentales. Madrid, 1990. Los testimonios directos más concluyentes de la Justicia durante la guerra y desde posiciones diferentes, Avilés, G.: Tribunales Rojos (vistos por un abogado defensor). Barcelona, 1939. Justice, (la) du "Frente Popular" par trois deputes aux Cortes. Prefacio de Henry Lamery, Paris, 1937. Moreno Gonzalez, R.: Yo acuso... (133 días al servicio del (iobierno de Madrid por... ex abogado Fiscal del Tribunal Popular de Málaga). Tánger, s/f.. Ruiz Villapalana, A.: Doy fe... Un año de actuación en la España nacionalista. Ediciones Españolas, 1938. Escobal, P.: Las sacas: España, 1936. New York, 1936. Oficina Informativa Española: El orden en la legalidad republicana. Madrid, 1948. La legalidad en la República Española. Madrid, 1948. El Frente Popular en España. Madrid, 1948. Bethune, N.: The crime on the road Málaga-Almeria. ¿1937?. Le bombardement des villes ouvertes. Paris, 1938. Bombardements et agresions en Espagne, Juillet, 1936-1938 (norld commitee against war and Fascism). Paris, 1938. Brouwer, J.: A famous dutch writer denounces rebel atrocities. N,P. 193-?. Words of indignation on truth. Valencia,
} 
Resulta inútil e infructuoso, y a la larga perjudicial escribir "cinco" renglones del "terror" republicano y "veinte" del "terror nacionalista", en trabajos que pretenden abordar el primero. Es igualmente estéril, desde la naturaleza del paralizado y cada vez mas limitado -territorialmente- Estado republicano, esgrimir como punto de razón, que se proclamase o no el Estado de Guerra. ¿Quién hubiese consentido entre las fuerzas republicanas tal evento? ¿Quién ejecutarlo? ¿Podía haber frenado las muertes republicanas al menos durante los primeros meses de guerra?. Que la zona franquista lo proclamó, lógicamente. ¿Quién dirigió el golpe de Estado? Las medidas severísimas y brutales fueron sus características congénitas.

Me parece especialmente peligroso el recurso "metodológico" sustentado en que una desideologización absoluta del conocimiento hace difícil, por no decir imposible, el estudio de la represión. He repetido, que no veo más lejos de deformaciones teóricas, de apriorismos o subjetivismos, al que investiga sobre César y Bruto o la Guerra Civil. Es más, avanzado el tiempo, incrementadas las fuentes, ¿cómo puede certificarse con "rigor", hacer historia, sobre la represión nacionalista y no con la republicana?.

La violencia republicana en la guerra civil tampoco puede ser dilucidada -menos justificada-, con una micro-tesis weberiana; el Estado tuvo derecho a la defensa frente a la agresión, con la cual el marco jurídico-constitucional obtiene para sí la fuente del Derecho con que responder al golpe de Estado. El Estado republicano en Febrero de 1936 se asentaba, frágilmente, en unas clases "potencialmente" revolucionarias, instituciones y grupos dispuestos a superar la estrecha legalidad... Un Estado en tales condiciones es "susceptible" de ser atacado, y además, desde varios frentes. Que fue destrozado por un golpe de Estado militar y fascista. Sin duda. Situada la legitimidad, volvamos a la realidad ${ }^{16}$.

1936?. Castilla, J.: La Justicia Revolucionaria en España. Buenos Aires, 193-?. The crime of Francisco Franco. New York, 1938? . Foreign journalist under Franco's terror. London, 1937. Getino, L.G.: Justicia y caracter de la guerra nacional española. Salamanca, 1937. Mc. Govern, J.: Terror in Spain; how the communist international has destroyed working class unity; undermined the fight against Franco, and suppresed the social revolution. London, 1937. Madrid, the "military" atrocities of the rebelds, a record of massacre, murder, mutilation (Labor Party Great Britain). London, 1937. Muntadas, U.: Sobre las muertes causadas en la población civil por la revolución comunista española. Sevilla, 1938. Berryer, (pseud.): Revolutionary Justice in Spain. London, 1937. España, $\mathbf{M}^{\circ}$ de Justicia.: Por una justicia popular humana y democrática. Barcelona, 19--?. Spain and the world. The innocent victims of fascists bestiality need your solidarity. London 1937.

${ }^{16}$ Dirigir el debate sobre la represión al marco jurídico-político, a la legitimidad de poderes, puede resultar infructuoso, no exento de cierta ingenuidad. La República, el Frente Popular, fue expresión electoral del voto nacional en el ámbito de la Constitución. Los avances sociales limitados por la misma moderación republicana y los frenos de las clases dominantes progresaron incontenibles. Un golpe de Estado militar, entroncado en los modelos fascistas europeos, destrozó y conquistó el sistema democrático. También ellos blandieron causas "legales" para la insurrección: las "falseadas" elecciones de Febrero de 1936 y las presentaron al mundo. Todavía hoy se utilizan estos "argumentos". Eso sí: sin excederse. Ellos venían a salvar cosas más "legitimas": el urden, la propiedad, la religión, el caos, la España comunista... El mensaje circuló más claro: restaurar los atacados intereses. Detenerse a elaborar las causas "justas" pasó a un segundo plano. Las democracias eran en Europa a la altura de 1930, desfallecidos regimenes. Hubiese resultado más útil prepararse para defenderla -si se creía en la República-, que clamar contra el militar 
El intento del fascismo de encauzar un Estado de caos y destrucción, nunca dejó de ser una patraña franquista. pero en el marco de la política internacional fue, al menos, útil. ¡Cuánto hubiese dado Azaña por presentar una imagen más equilibrada del Régimen entre las potencias europeas!.

Es inaudito que Salas Larrazabal utilize la afirmación "El Estado no estaba ni secuestrado ni inválido"'? zarlo del terror y la muerte: el Estado, el gobierno, las instituciones republicanas "no inválidas" planificaron y ejecutaron las acciones violentas. Lo cual no es óbice para que uno de los mas firmes defensores del "caos" del Estado republicano, sea inmediatamente después, el propio Salas ${ }^{18}$.

Los meses más críticos de la guerra, aquellos que correspondieron al Gabinete Giral y fases de Largo Caballero, reúnen una unamidad poco común": la "desarticulación", "incapacidad"... del Estado republicano. Intentar "apuntalar" un Estado sólido y responsable en esta etapa es vano intento (otra cosa es que legalmente rijan las instituciones de la República): "reinaba gran confusión en el terreno político, económico, administrativo y militar" (Ibarruri); "la autoridad del gabinete del Doctor Giral no rebasaba casi los alrededores de Madrid" (Broué-Temime); "Los elementos defensivos del Estado de que pudiese disponer el Estado o estaban disueltos o aminorados..." (Azaña); "estaba instalado el gobierno y tenía un despacho nuestro compañero Prieto que a juzgar por su actividad era, por sí mismo, otro gobierno"; (Zugazagoitia). Jackson reconoce: "En la segunda mitad del año 1936 en el territorio que permanecía en manos del Frente Popular, tuvo lugar la revolución más profunda ocurrida desde el siglo XV". J. Aróstegui sintetiza: "Así, en suma, en los primeros meses de guerra, los fenómenos más característicos consisten en la ruptura violenta, por represión o descomposición de los anteriores centros del poder político legal, en una profunda alteración de las relaciones entre fuerzas sociales y sus situaciones en el sistema de dominación, en una desintegración de los sistemas coercitivos de Estado de Derecho y en el desbordamiento de las prácticas represivas"19.

Etiquetar el "terror" republicano por la acción de bandas, delincuentes o grupos "incontrolados", mientras el gobierno reconstruye los aparatos de Estado. me sugiere

desaprensivo. Ahora bien, si debemos asignar los papeles respectivos ante la Historia, la verdad se asienta en un régimen legal atacado por una facción civil y golpeado por una parte del Ejército. Sólo que Hitler llegó al poder por las umas y no deveninos de ello el rechazo al sistema participativo.

${ }^{17}$ Hemos utilizado de este autor uno de sus últimos trabajos sobre el tema que nos ha parecido más sintetizado de su pensamiento : Salas larrazabal, R.: " $L$ a represión en territorio republicano", en Aportes. Revista de Historia Contemporánea. № 8. 1988. Pp. 53-64.

${ }^{18}$ El "caos" y la justificacion "legal" y juridica que se observa en este trabajo fue contestada con el franquismo tachando de "ilegales" las elecciones de Febrero de 1936, asi tenian las manos libres y una base presuntamente legitimadora para la intervención militar. Estado Español. Ministerio de la Gobernación: Dictamen de la Comisión sobre la ilegitimidad de poderes actuantes el 18 de julio de 1936. Madrid. 1939. Idem. Apéndice I. El dictamen de la Comisión sobre ilegitimidad de poderes actuantes el 18 de julio de 1930. Madrid, 1939.

${ }^{19}$ Aróstegui, J.: "I os componentes scciales y politicos", en La guerra civil española. Cincuenta años después. Barcelona. 1985. Päg. 49. 
un restringido punto de vista que puede inducir a una visión "ideológica". Una especie de golpe de pecho ante la conceptualización franquista. La delincuencia nada tiene que ver con la República. Razonamiento diferente es que encontraron un marco propicio para sus actos. Que las autoridades de la República reprobaron, lloraron, las matanzas contra presos, clero, personalidades o simples bases de la derecha, está fuera de toda duda. No sólo por convicción moral, los "tranquilos doctores" como los denominó Kolstov, sino por lo que suponía de gravísimo error político nacional e internacional. La marea humana no estaba en los despachos de los ministros...

La valoración ética de la muerte determinada por el origen social del ejecutante/ejecutado, supone otro elemento de debate en la violencia. ¿Quién era más responsable en el ejercicio de la muerte: el abogado, propietario, concejal, rico, industrial, intelectual formado, o el jornalero, aparcero, peón, sin propiedad por vida, representante de mísera familia, pobre de siglos, analfabeto y posiblemente sin conciencia de clase? La muerte es reprobable en cada caso. Desde ambas posiciones la guerra civil condujo a tal dinámica en la lucha de clases que no bastaba ser "bueno", "malo", respetuoso con los obreros, malvado o no con el patrón. El drama era ser patrón u obrero. La violencia consumada ejercía, por un lado determinado, implacable señal inanimada de tráfico. No obstante, la realidad de nuestra sociedad convierte al rico propietario en un agente social mucho más consciente, que sigue valorando escasamente la vida de "sus" u otros "obreros" o "jornaleros". Los "señoritos" fascistas constituyen una imagen imperecedera de la brutalidad, el odio, y la maldad de quienes se proclamaban católicos y españoles.

\section{LA VIOLENCIA CAMPESINA Y LA II REPUBLICA}

Los políticos republicanos entendieron que la "modernización" de las estructuras agrarias, constituía un elemento esencial para una ordenación adecuada de la economía nacional. Por recientes trabajos de historiadores de la economía (M. Aceña, F. Comín, Grupos de Historia Rural...), sabemos, no sólo la pesada carga que la hacienda primorriverista había otorgado al nuevo régimen, sino las leves modificaciones que en política económica estableció la II República: "Dada la situación real de la economía española en aquellos años era extremadamente complicado combatir el desempleo o fomentar el crecimiento económico al tiempo que se trataba de equilibrar el gasto presupuestario ${ }^{-20}$. A la luz de éstas investigaciones algunos "clásicos" de la Reforma Agraria deben ser seriamente revisados.

Hubo "hechos" de política agraria más que transformaciones del sistema. La ley de Términos Municipales, Jurados Mixtos, jornada de 8 horas, pagas extraordinarias, ley de laboreo forzoso... Al mismo tiempo, los sabotajes, la violencia caciquil, el triunfo derechista en 1933, permiten entender situaciones en que la Ley no actuaba

20 Comin, F. y Martin Aceña, P.: "La politica monetaria y fiscal durante la Dictadura y la II República". en Papeles de Economía Española. La nueva cara de la Historia económica en España. № 20. 1984. Pp. 236-261. 
con la contundencia que la miseria, las difíciles condiciones de vida que padecían los jornaleros, aparceros y campesinos hubiese sido preciso. ¿cómo extrañarse de la toma de tierras en 1936?. Así pues, la asignación al I.R.A. de pocos fondos, no se debe culpar ni al presupuesto público al Ministro de Hacienda, sino al poco entusiasmo de los gobiernos republicanos por intensificar el reparto de tierras ${ }^{21}$.

Quizás en la lucha obstinada en el medio rural, llame la atención, por encima de todos, la aplicación del Decreto de Laboreo Forzoso. Una lectura pausada de la amplia documentación existente en aquellos archivos municipales que hoy todavía subsisten milagrosamente entre la desidia de los equipos de gobierno (de todas las tendencias), no deja de impactar al investigador y llenarlo de cierta zozobra premonitoria.

Reconoce P. Preston, que esta limitación por el Estado del derecho de los propietarios a usar sus tierras "indignaron" especialmente a los latifundistas ${ }^{22}$. La afirmación es cierta, el problema es que no todos eran latifundistas, y que muchos de éstos escapaban al control mientras era sometido, como establece el Decreto, su caso no a las competencias municipales, sino a la Comisión Técnica Central de Laboreo Forzoso, Subsecretaria del Ministerio de Agricultura, Industria y Comercio. Por el contrario, la comisión de Policía Rural vigilaba las medianas y pequeñas propiedades. Quizá lo más peligroso y a corto plazo objeto de "venganza" eran las "denuncias" de jornaleros sobre fincas pequeñas no labradas, remitiéndose al estricto contenido del Decreto.

A finales de 1932 y sobre todo a principios de 1933, las Comisiones de Policía Rural presididas por el Alcalde "con los vocales obreros y los vocales patronos", realizaban inventario de la marcha del "laboreo"y acusaban con insistencia al terrateniente comarcal, el cual reclamaba con sus abogados, retrasando la resolución deseada. Los centenares de expedientes, formularios, a máquina, a mano, reflejan una severa discordia:

Don...formula la denuncia al propietario... de una finca de tres fanegas de tierra aproximadamente sembrada de trigos al parecer tiene una labor de rastra, pero tratándose de un pegujar temprano, le hace farta (sic) la labor de brazos por tener mucha hierva (sic) por lo que el denunciante la encuentra dentro del laboreo forzoso

Minuciosas averiguaciones fueron realizadas contra demasiados pequeños y medianos propietarios.

El 15 de agosto por mandato del Subsecretario, se obliga a un propietario de 2 He. a levantar un rastrojo de trigo en el olivar, si en el plazo de 8 días no lo hiciera,

\footnotetext{
${ }^{21}$ Comin, F. y Martin Aceña, P. Ibidem. Otras innovaciones más recientes: Grupo de Historia Rural: "El sector agrario hasta 1935", en Estadísticas históricas de España. Siglos XIX y XX. Madrid, 1989. Pp. 91-129. Comin, F.: "El sector público". en Ibidem. Pp. 397-460. Martín Aceña, P.: "El sistema financiero", en lbidem. Pp. 365-394. Puede consultarse un amplio capítulo de bibliografia en los respectivos trabajos.

${ }^{22}$ Preston, P.: "La guerra agraria en el Sur", en Preston,P. (ed), Revolución y Guerra en España, 1931-1939. Madrid, 1986.
} 
"la Comisión de Policía Rural suplirá la omisión enviando yuntas y luego obreros a costa del interesado, de conformidad con lo dispuesto en el Decreto de 23 de mayo de 1932, fijando en este caso la Sección Agronómica el máximo de jornales a emplear"23. Transcurrido el año 1933. el nuevo gobierno inició el desmantelamiento de las reglamentaciones legislativas del Primer Bienio. Desaparecen, pues, las Comisiones señaladas. Es el tiempo del Partido Radical, Acción Popular (la CEDA), la derecha ocupa los casinos, pasea por las plazas,se mofa de los jornaleros...

Creo que historiadores serios magnifican la labor de la CEDA tanto entre los latifundistas como entre los pequeños propietarios. Especialmente en el Sur, donde ésta volcaría sus influencias, por ser Andalucía posible región de R.A. y zona relevante para el Alzamiento militar ${ }^{24}$.

Ni la articulación política de la derecha católica lo permitía, ni era tan eficaz, ni las antiguas zonas de "dominio" caciquil podían superar, en poco tiempo, su funcionamiento "autárquico", ni el Estado español estaba fortalecido por clases de tanta y capacitada coordinación. Ciertamente hablamos de funcionamiento y operatividad antirrepublicana o anticampesina, no de coherencia ideológica y defensa de intereses.

Los informes de los alcaldes emitidos entre 1937-1939, sobre las personas muertas en sus respectivos municipios, presenta con gran simplicidad y acierto, el apartado "ideología": derechas, -apuntaban- junto a propietario; labrador o campo, otros precisan políticamente: "fascista", o "extrema derecha", "de orden y muy religioso"... , la Causa General en las declaraciones testificales solicita la afiliación política, que coincide, en parte, con los referidos "informes", ¿qué resulta de ello?.

Una distribución irregular del dominio e influencia de la derecha, y aún mas, al igual que las antiguas sociedades de resistencia entre los obreros, la CEDA, por ejemplo, es una organización interclasista, y en modo alguno agraria, sobresaliendo en aquellos pequeños municipios de influencia caciquil estable y el "cacique" es de A.P., sin embargo, igual puede ocurrir con el Bloque Nacional, el Partido Radical o los Agrarios.

En zonas "latifundistas" clásicas, están organizados los Comités del Bloque Nacional, de A.P. y los Agrarios. No podía ser menos, jla derecha unida!, y para una mejor identificación política ante el pueblo, de los miembros de las "nuevas" derechas, estos cargos reformados detentaron concejalías en la Dictadura. En

${ }^{23}$ Archivo Municipal de Pizarra (AMP), Archivo Municipal de Alora (AMA). Archivo Municipal de Vélez Málaga (AMVM), Archivo Municipal de Málaga (AMM), Archivo Municipal de Antequera (AMAn)... Los dos primeros sin ordenar, relativamente bien el tercero y bien los dos últimos. Servicio Agronómico de la Provincia de Málaga (AMM). Documentos: Ministerio de Agricultura, Industria y Comercio. Subsecretaria. Comisión Técnica Central de Laboreo Forzoso. AMP, AMA, AMVM. Denuncias. conminaciones...

${ }^{24}$ Sevilla Guzmán, E.: La evolución del campesinado en España. Barcelona, 1979. Sevilla Guzmán. E. y Preston, P.: "Dominación de clases y modos de cooptación política del campesinado en Éspaña", en Agricultura y Sociedad. № 3. 1977. Maurice, J.: La reforma agraria en España en el siglo XX. Madrid. 1975. Garrido, L.: Colectividades agrarias en Andalucía: Jaén, 1931-1939. Madrid, 1979. Montero, J.: La CEDA. El catolicismo social y político en la I/ República. Madrid, 1977. 
cacicatos más "rurales" A.P. es mayoritaria en relación a los citados grupos de notables, solo que por sí mismos, inoperantes en política local y general ${ }^{25}$. Más interesante puede resultar la aparición del Partido Radical, cuyo triunfo en las elecciones de 1933 fue manifiesto.

Un dato resulta significativo. la situación que se establece en aquellos pueblos donde la estructura de Falange Española (los escuadristas) está relativamente presente. Los propietarios aparecen calificados como "apolíticos". Lo cierto es que la CEDA fue mucho mas influyente tras el triunfo del franquismo. Pueblos enteros afiliados al catolicismo social fueron incapaces de defenderse frente a los ataques republicanos. En la guerra pudo constatarse la distancia entre las grandes frases y la mínima protección personal y social.

La cuantificación de la Causa General revela mas muertos de la CEDA que de otro partido. Unían dos allegados lúcidos para el pueblo: propietarios y católicos. Como señala Frances Lannon: "fervientes y orgullosos defensores de la Iglesia -no de su doctrina-, eran la CEDA, tradicionalistas y B.N., y con su negativa a contemplar cambios del sistema provocativamente cruel e ineficaz de las relaciones de propiedad en las zonas latifundistas (...), es un esfuerzo baldío que los historiadores pretenden que la iglesia no era antirrepublicana (...)".

El triunfo del Frente Popular intensificó las complicadas relaciones entre propietarios, labradores, jornaleros, aparceros, ayuntamientos.

Las renacidas Comisiones de Policía Rural, en nombre de las corporaciones socialistas, remiten a los terratenientes, grandes propietarios, pequeños y medianos, nuevas notificaciones de cuya lectura no es difícil reconocer esos síntomas que preludían la aguda expresión de la violencia: la guerra civil.

Los documentos, a máquina, oficiales, aunque sin sello del Ayuntamiento, dicen textualmente:

"Quedo enterado de la notificación de la Comisión de la Policía Rural conminándome a invertir cien jornales aproximadamente de caba por limones y naranjos de una huerta". Firma del receptor.

Centenares de notificaciones orientadas a la obtención de una banda que va desde 30 a 200 jornales. De la denuncia se ha pasado a la conminación del propietario que ha incumplido el Reglamento o no lo ha iniciado tras el triunfo del Frente Popular.

En abril de 1936 otras cédulas precisan con más exactitud las indicaciones de la Comisión aunque rebajando a 2 días los plazos para las reclamaciones:

"Sr. ...

Nombre de la finca Extensión

Operación a realizar

Observaciones

Realejo

6 fancgas

Escardeo de trigo y cebada

40 jornales

\footnotetext{
25 Caso ejemplar puede ser Antequera. donde confluyen todos los partidos y cada cual cjerce su influencia en pueblos diferentes de la gran Comarca, en este surco intrabético.
} 
El mismo mes, un telegrama de Línea de la Guardia Civil de Fuengirola cuenta como el Alcalde de Mijas ordenó detener a un vecino por negarse a abonar jornales a 38 obreros que sin su autorización trabajaban una finca de su propiedad. Informa el teniente, que tras hablar con el gobernador civil había sido puesto en libertad dicho vecino, "existe tranquilidad en la población". Días después el mismo teniente "da cuenta de la delicada situación de esta localidad" al Teniente Coronel Primer Jefe de la Comandancia de Málaga.

A los conflictos sociales en el campo andaluz durante el Frente Popular, hemos podido acceder a ellos al obtener la información, del año 1936 en la Dirección General de la Guardia Civil, primero de las líneas que abarcaban varias provincias andaluzas, después de la Guardia Nacional Republicana en el Frente de Málaga, complemento, hasta ahora desconocido, a los numerosos trabajos ya realizados.

Los informes de los Jefes de Línea son altamente indicativos de la realidad que se vive previa al levantamicnto militar.

De notable reserva, resulta una comunicación de un teniente en Torre del Mar sobre la vigilancia a que somete ciertas noches (abril de 1936) a las "juventudes socialistas y comunistas", reunidas para "hacer instrucción militar" manejando instrumentos que simulan fusil y cuya dirección corría a cargo de un ex miembro del Tercio. Que tales actos, contemplados por él y otros dos testigos tienen lugar en la Caleta de Vélez, el Morche, Mezquitilla, observándose grupos que hacían ejercicios militares en pleno día. Actos, según el citado oficial, "tendentes a una subversión"26.

En abril, mayo, junio de 1936, las huelgas, enfrentamientos con la Guardia Civil, ocupaciones de tierras para trabajarlas..., activan el estrépito.

\subsection{La represión rural}

Todos los investigadores se mostrarían de acuerdo si señalase que la represión en el medio rural es "primitiva", violenta e incluso cruel, y mas intensamente aguda en comarcas latifundistas que minifundistas. Pero hay que llegar más al fondo rechazando la "tesis" que destaca los "resentimientos personales" como causa destacable de las muertes ("lesis" que hemos podido comprobar entre las gentes más humildes represaliadas o no, de ambos bandos). La represión republicana rural es ciertamente más primitiva, y más proclive a ejercer en zonas latifundistas, pero esto nos sitúa en unas propuestas fundamentalmente economicistas y limitadas históricamente.

La represión, como Marx dijo de las clases sociales, es de naturaleza histórica, y ésta no puede limitarse a una coyuntura de perfiles políticos. La violencia es

\footnotetext{
${ }^{26}$ Dirección General de la Guardia (ivil. Carpeta entregada al Autor tras solicitud. Línea de Arriate: sobre petición de auxilio por el Sr. Presidente de la Gestora de este Ayuntamiento. Enero, 1936. Línea de Teba: Copia de un escrito en que cuenta un hecho relacionado con la situación político-social. Enero. 1936. Telegrama sobre mitin en Torre del Mar, "ataca Casa Larios". Enero, 1936. Línea de Coin: dando cuenta del asalto y destrucción del interior de la Iglesia de Guaro. Marzo, de 1936. Línea de Torre del Mar: Informe sobre el proceder y conducta de las Juventudes Socialistas y Comunistas. Abril. 1936. Málaga-Poniente. Cuenta el haber sido asaltado un tren, Mayo 1936...
} 
síntoma de un malestar de tiempo largo con hitos en la Guerra de la Independencia, en las "cuerdas de presos" carlistas, en el juntismo de $1835,40,43,54,56,68$, en la revolución de Loja, en la prepresión popular de 1868, en la violencia del caciquismo..., y la geografía de esta presión no corresponde únicamente al Estado, en fases políticamente contrapuestas, "elementos civiles" han colaborado o han sido imprescindibles (y únicos), para forzar el cambio.

En 1936 la revolución y la contrarrevolución han alcanzado magnitudes históricas nuevas: son de masas y tocado el punto más álgido del proceso histórico. Ello no es que hiciese inevitable la guerra civil, pero sí mostraba, que en caso de que una coyuntura nueva y poderosa desencadenará hostilidades, la violencia iba a estallar como una espiga hecha.

$\mathrm{Y}$ estos acontecimientos históricos no se produjeron únicamente en zonas latifundistas. Terrenos de propios y de comunes, pequeños propietarios arruinados que sucumben por no poder hacer frente al prestamista, terrenos baldíos que convierten al campesino en un esclavo, utilización del Ayuntamiento por los grupos dominantes en pequeñas pero grandes cosas: el control del agua, disposiciones legales en materia de producción, medianos propietarios que utilizan a los jornaleros "a destajo" en condiciones muy duras y temporales, y en general, una fracción de poder que incluso ocupan un ámbito urbano distinto en los pueblos (ello hemos podido comprobarlo en la localización de los muertos "nacionalistas" siguiendo la calle, el número) debe unirse a ésto, y he aquí otra de las muestras de la concentración de poder, la relación de muertes aparecen, un elevado, a veces casi total porcentaje de individuos de una sola familia. que se habría caracterizado por el ejercicio del poder económico o político. No es necesariamente caciquismo, sino "familiarismo", enfermedad infantil del caciquismo.

Sobre el "primitivismo" campesino y la violencia que de ello se desprende, debe, igualmente, situarse en la "historia", en la realidad de las fuentes, las especificidades del pueblo, y la agresividad y violencia de los patronos. Cada tiempo y cada medio tiene su crueldad porque las causas que la engendra así lo establecen.

Pero, ¿existió una represión rural?, ¿la ejercieron los jornaleros contra su clase antagónica, los propietarios?, ¿fue este rígido esquema de la lucha de clases el que dirigió la represión en los pucblos?. Cuantificados más de cien pueblos andaluces, las conclusiones son complejas y atrayentes.

En la relación existente entre población activa masculina (tres hijos y mujer), y el número de muertos, nos aparece un mayor porcentaje en pequeños pueblos, de estructura minifundista, que en los grandes de estructura latifundista, con la peculiaridad que en la composición socio-profesional de los muertos en las zonas minifundistas predominan los campesinos frente a una diversidad mayor en comarcas latifundistas, siendo las zonas de mediana propiedad donde se registra el número más elevado de muertos por la violencia, no necesariamente rurales.

Los informes de los alcaldes, fuentes para el estudio de la represión junto a la Causa General, si bien globalmente uniformes, presentan algunas peculiaridades: 
desde el estrictamente socio-profesional, al político, sin abandonar el anterior ${ }^{27}$.

\section{LA IGLESIA Y LA II REPUBLICA}

\subsection{La represión sobre la Iglesia}

El mismo 23 de febrero de 1981 mientras un grupo de militares golpistas intentaba derribar el sistema constitucional, era elegido Presidente de la Conferencia Episcopal Española, D. Gabino Díaz Merchan, sacerdote de tendencia progresista en la Iglesia Católica. iQué evolución tan diferente habían experimentado dos de los pilares del fascismo español!.

En la redacción de objetivos para modernizar a España, los políticos republicanos creyeron que seria "el problema religioso" (unánimente) y la reforma agraria (mayoritariamente) los mas difíciles escollos a superar. No se equivocaron, pero, ¿y el problema militar?.

Las investigaciones sobre la Iglesia durante la República y la guerra civil han avanzado desigualmente. Desde la tesis de "persecuciones religiosas" (A. Montero $)^{28}$, pasando por las líneas mucho mas serias de "ecuanimidad y responsabilidad mutuas" (por ejemplo, H. Raguer) ${ }^{29}$, a los mejores trabajos que se han realizado hasta este momento, obra de F. Lannon ${ }^{30}$ Debo citar al margen, por su especificidad, las publicaciones imbricadas en el nuevo "espíritu" de la Iglesia y el papado polaco: aquella que convierte en "mártires" a muchos de los que profesando la fe católica, murieron violentamente en la guerra civil. Estos no fueron ejecutados por sus tendencias políticas, sino por su alineamiento con Cristo y la Iglesia. Activos representantes Cárcel Ortí, J. A. Gallego y otros. Esta última tendencia "ideológica" no me parece sólo fuera de los instrumentos de análisis adecuados sino "políticamente" posicionada ${ }^{31}$.

El estudio de la represión ejercida sobre la Iglesia Católica española resulta

${ }^{27}$ Informe del General Cuesta. Documento farragoso y falso.

28 Montero Moreno, A.: Historia de la persecución religiosa en España, 1936-1939. Madrid, 1961.

29 Raguer, H.: "I a Iglesia española en la II República", en Arbor, Nums. 426-427. Mayo-junio 1981. Pp. 195-210. "Los Obispos españoles y la guerra civil". Arbor tomo CXII. Nums. 439-440. Julio-agosto, 1982. “El Cardenal Gomá y la guerra de España", Arbor, № 436. Pp. 44-81. La Espada y la Cruz. La Iglesia 1936-1939. Barcelona, 1977. Revista Historia 16, N 13. Madrid, 1986, "La Iglesia durante la Guerra", articulos de investigación y especialización de J. M. Laboa, H. Ragner, V.M. Arbeloa, M.T. Rodríguez, J.M. Margenat.

${ }^{30}$ F. Lannon, "Modem Spain: the proyect of a national catholicism", en S. Mews (dir), Religion and national identity. Oxford, 1982. "The scxio-political role of the Spanish church. A case study", en Journal of Contemporary History. XIV, $\mathrm{n}^{\circ}$ 2. 1979. "la cruzada de la Iglesia contra la República", en Preston, P. (ed)." Revolución y guerra en España, 1931-1939. Madrid, 1986. Privilegio, persecución y profecía. La Iglesia Católica en España, 1875-1975. Madrid, 1990.

${ }^{31}$ Carcel Orti, V.: La persecución religiosa en España durante la Il República (1931-1939). Madrid, 1990. A.A.V.V.: Historia de España. La guerra civil. 1936-1939. Madrid, 1989. 
especialmente complicado. El carácter de cruzada, la "cristianización" de la guerra, el alineamiento nacional y pontificio (Pío XI) de la Institución con los subleva$\operatorname{dos}^{32}$... impide, en multitud de casos, separar de un acontecimiento concreto, en el análisis de las fuentes, la causa civil y religiosa. Este consentimiento asumido por el ejército sublevado y la Iglesia Legitimadora y que explicaría, en parte la violencia contra la "Iglesia oficial", está sufriendo un proceso de modificación por parte de la Institución. Los sacerdotes fallecidos a causa de violencia fueron inmolados por su carácter religioso, nunca "político" (lo que obligaría a quitar de miles de tumbas el "muerto por Dios y ipor España?). Las recientes beatificaciones del Pontífice Católico, Juan Pablo II, se mueven en esta orientación. A los miembros de la institución religiosa habría que comenzar a llamarles -según estas propuestas-, "mártires" y "perseguidos", lo que abre laberínticas posibilidades de investigación (el martirio de los seglares, además).

Esta visión "filosófica" libera de responsabilidad política alguna a la Iglesia. Sacerdotes y seglares, en la Guerra Civil: sufrieron muerte únicamente por su carácter "religioso", creer en Dios, o practicar el culto. En consecuencia, su vida es motivo de ejemplo para la comunidad cristiana. Así se irán elevando al martirio: "No cabe la menor duda que durante la persecución hubo verdaderos mártires, pero quizá no todas las víctimas lo fueron (...). Cuando la Iglesia concede el honor de los altares a sus mártires no hace un proceso de los asesinos, ni los condena. sino que emite un juicio sobre las virtudes heróicas del mártir que murió perdonando, como Cristo en la Cruz, y como ha hecho la Iglesia siempre con sus verdugos, porque predica la ley del amor y del perdón y no la del odio y la venganza" ${ }^{\text {"3 }}$.

El conocido y bien documentado (cuantitativamente) libro de A. Montero, pretende alejarse del método "teológico", pero sin dejar de reconocer el "contenido martirial" de las victimas cristianas: "Creo que es impropio hablar de víctimas o mártires de la Guerra Civil, término político y reductivo, cuando en realidad debiera hablarse de mártires o víctimas de la persecución religiosa".

Más profundamente cristianizadora sería la propuesta sostenida por un sector de investigadores eclesiásticos: "añadiré que el acto martirial ha de analizarse, aún historicamente, desde la fe, si se quieren asimilar sus riquezas; hacerlo de otro modo es adulterarlo, proceder sicmpre ilícito. en historia como en todo"34.

Tales planteamientos, que de seguir adelante, volverán a abrir un "cisma" social en España (y las beatificaciones ya llegan hasta la Revolución de Octubre), conduce inexcusablemente a la identificación entre Iglesia-Movimiento Nacional-Franquismo. En las zonas liberadas, la cruz entraba junto a la espada, y la República era, per se,

\footnotetext{
${ }^{32}$ Rodriguez Aisa. M.L.: El Cardénal Gomá y la Guerra de España. Aspectos de la Gestión pública del primado, 1936-1939. Madrid, 1981. Aneloa, V.M.: La Semana Trágica de la lglesia en España. Barcelona, 1976. Irriharren, J.: Documentos colectivos del Episcopado Español (1874-1974). Madrid, 1974. Garrido, R.: El Cardenal Segura y el nacional-catolicismo. Barcelona. 1977. Arbeloa, V.M.: La Iglesia en España, ayer y mañana. Madrid. 1968. Benaveides, D.: El fracaso social del catolicismo español. Arboleya Martínez, 1870-1951. Barcelona, 1974.

${ }^{33}$ Cárcel Orti, V.: La persecución religiosa en España durante la Il República... op. cit. Pág. 36.

${ }^{34}$ Lisardo, G.: Martirologio malaginense. Málaga, 1988.
} 
antagónica, enemiga y condenable por la Iglesia Católica. Ello explicaría, claro está, que la "persecución" a que fue sometida la institución en las zonas republicanas fue "copiosamente" recompensada por el Nuevo Estado hasta extremos que jamás dispuso la Iglesia.

Esta escuela que presenta a la Iglesia como víctima "gratuita" de una legislación y una práctica antirreligiosa es sustentada, por ejemplo, por Palacio Atard ${ }^{35}$.

El laicismo constitucional, los ataques a iglesias y conventos, el matrimonio civil, han sido esgrimidos como la razón lógica del alejamiento y enfrentamiento con el poder civil. Para A. Gallego y otros, "que como entonces se dijo hasta la saciedad, en la zona republicana se reaccionó contra el alzamiento militar, distinguiendo los símbolos históricos de la contrarrevolución, entre ellos todo lo que tuviera que ver con la Iglesia y, entonces, sí, la jerarquía eclesiástica respondió respaldando a los sublevados; algunos obispos, uno o dos meses después de que comenzara la guerra"36.

Consecuentemente, la Iglesia "se vio obligada" a una legítima defensa, que sólo ejecutó tras las duras masacres de sacerdotes en las primeras semanas de guerra.

F. Lannon rectifica tales posiciones: "las raíces de la declaración oficial de la Iglesia española en julio de 1937, en defensa del Alzamiento de 1936 y en oposición a la causa republicana en la Guerra Civil hay que buscarlas más allá de la horrorosa matanza de religiosos en territorio republicano en los primeros meses de la guerra y de la legislación de 1931-1933, y retrotraerlas a los valores políticos tradicionales y a las estructuras socio-económicas del catolicismo español (...). A la Iglesia le preocupaba esencialmente su supervivencia intelectual y su vigor, sus opciones para lograr ambos objetivos estaban seriamente limitadas por su pasado reciente y por la actitud de sus detractores y enemigos ${ }^{37}$.

De la cuantificación de A. Montero, así como de las relaciones presentadas por los Boletines Oficiales de los Obispados y otros documentos complementarios, hallamos una primacía represiva sobre el clero secular.

Aunque algunos párrocos, coadjutores, ecónomos fueron "sacados" de prisiones o ejecutados, no parece desatinada la deducción según la cual fue en los pueblos -la represión rural-, donde se dejo sentir con plena intensidad la ola de violencia: "donde

\footnotetext{
${ }^{35}$ Palacio Atard, V.: "La Segunda Republica y la Iglesia", en Aldea, Q., Marin, T., y Vives, J. (dirs): Diccionario de Historia Eclesiástica de España. Madrid, 1972. II. 1.179-84, reimpreso en sus Cinco Historias de la República y de la Guerra. Madrid, 1973, 39-60. Una interesante relación de folletos, informes... sobre la Iglesia "perseguida" en España, en Harvard University Library. Author and Title Listing and Listing by place of publication. The Blodgett collection of Spanish Civil War Pamphlets. Cambridge, Massachussets. Harvard College Library.

${ }^{36}$ AAVV.: Historia de España. La Guerra Civil. (1936-1939). Madrid, 1989. Pág. $40 . \quad$.

${ }^{37}$ Lannon, F.: La Cruzada de la Iglesia... Pp. 41-58. La historiografía más clásica ha reconocido la "ferocidad" de la represión eclesiástica, asi como la "general subordinación de los sacerdotes a las clases altas". Thomas, H.: La Guerra Civil Española. Barcelona, 1976. Pp. 295 y ss. Jackson. G.: La Repuiblica Española y la Guerra Civil. Méjico, 1967. Pág. 245. Broue-Temine.: La Revolución y la Guerra de España. Madrid, 1977. Pág. 139. Blanhard, P.: Freedom and Catholic Power in Spain and Portugal. Boston, 1962. Pp. 11-12.
} 
la lucha de clases era más aguda. la práctica religiosa era impensable para los no propietarios. Ese era el caso -reforzado por la militancia anarquista y socialista-, de las regiones latifundistas del sur, que era donde se localizaron habitualmente tanto la violencia antiseñorial como la violencia anticlerical entre la década de 1870 y 1939 "38.

El clero regular, el que no está sometido al obispo, sino a sus superiores modifica los índices. Aquí el porcentaje es fundamentalmente urbano, ciudades o grandes pueblos. Las órdenes más castigadas son las relacionadas con la enseñanza y corresponde a un nivel (el clero) superior en cultura, formación e influencia.

Como subraya el antropólogo británico Pitt-Rivers en el prefacio de su estudio sobre Grazalema: "La situación entre política y religión, tal y como la concebimos en nuestra propia sociedad, no tiene validez antropológica (...) en el contexto español. La práctica católica y el conservadurismo político eran partes inseparables de la misma realidad cultural, confrontados por su reflejo burlón en universos culturales excluyentes, en los que el radicalismo político y el extrañamiento de la Iglesia se reforzaba mutuamente" ${ }^{" 39}$.

La represión, la violencia, el odio... tiene en los pueblos, en los núcleos rurales, motivaciones tan complejas como simples, y el ejercicio de esta violencia desde los métodos más elementales, por su inocencia, o los más brutales.

Irán apareciendo prohibiciones del toque de las campanas, de ceremonias fúnebres, de bodas.... y es que el clero aparecía siempre en la pomposidad de un entierro para "ricos" y se personaba, apenas un instante, en la casa del pobre, y sonaban las campanas para unos sí y no para los demás, eran distintas las bodas, los bautizos...

En un marco socialmente analfabeto e influido por las ideas, muy básicas, anarquistas o marxistas, de divisiones sociales marcadas, el Párroco y los religiosos resultaban ser los "intelectuales orgánicos" de los poderosos, de los pudientes (y éstos no tenían que serlo en exceso) lo que les iba separando de esa inmensa masa de campesinos o jornaleros pobres. El cura no era tan frágil en la conceptualización mental y social como el propietario o cacique, ellos podían ser buenos o malos (así se decía sólo por el tratamiento directo y personal hacia los trabajadores), pero eran fácilmente discernibles e identificables: eran los patronos, al fin y al cabo. El cura, no. Su influencia sobre las conciencias del pueblo no era desdeñable y dotaba de coherencia y raciocinio al discurso clasista, llamaba a la paciencia, prudencia y al orden social, sin poder ser descubierto, a no ser por la minoría más consciente de las sociedades obreras.

No son otra cosa los insultos nocturnos, en el resguardo de la obscuridad, al sacerdote, la profanación de sepulturas de muchas parroquias, impedir que se celebraran los oficios, lucha de los ayuntamientos para evitar la salida del Corpus Christi, pasar junto a las imágenes sin quitarse los sombreros de las cabezas, la

\footnotetext{
${ }^{38}$ Lannon, F.: Privilegio, persecución... op. cit. Pág. 37.

${ }^{39}$ Pitt-Rivers, J.: Grazalema: un pueblo de la sierra. Madrid, 1989.
} 
impiedad de los municipios, exigir permiso para celebrar entierros... ${ }^{40}$.

De las batallas sociales no se libraron ni las imágenes ya que en algunos pueblos fueron salvadas por ser "republicanas" (Santiago y Dolores), frente a las regaladas, por ejemplo en Alozaina, por un marqués cacique, naturalmente destruida. "Así pues, si miramos más allá de la legislación, de una parte, y de las declaraciones de la jerarquía, por otra, y al margen de la cronología harto restrictiva de 1931-1936 (o pero aún, de 1931-33), es evidente que las relaciones de la República y la Iglesia no eran las de un agresor gratuito con una victima inocente" 41.

${ }^{40}$ De la consulta de numerosos archivos locales podemos destacar ciertas polémicas y tensiones permanentes: Archivo Municipal de Benamocarra, Alcaldia constitucional, 8 de noviembre de 1932 . "Al Ilmo. Sr. Vicario General del Obispado". Archivo Municipal de Casarabonela. Saludo. El alcalde. 19 de diciembre de 1932. Negociado 1. N". 576. "Sr. Cura encargado de esta parroquia". Archivo Municipal de Alhaurin el Grande. Alcalde constitucional. Abril-noviembre de 1932. y correspondencia del Párroco: “Al Sr. cura Párroco". "Al Sr. Vicario general del Obispado"...

${ }^{4 t}$ En este sentido, debemos reseñar algunos libros relevantes. Maritain, J.: Los rebeldes españoles no hacian una guerra santa. Madrid, 1937. Iturralde, J. de.: La guerra de Franco, los vascos y la Iglesia. San Sebastián, 1978. Marquina, A.: La Diplomacia Vaticana y la España de Franco (1936-1945). Madrid. 1983. Lannon, F.: La cruzada de la lglesia... op. cit. pp 45-58. Thoming. J.F.: ¡Mercy and Justice!. A reply to 450 protestants bishops and clergymen, prepares at the suggestion and with the approval of Michael J. Curley, Archbishop of Baltimore. New York, 1939. The persecution of Protestants in Fascist Spain (American friends of Spanish Democracy). Washington, D.C. 1936?. Ossorio y Gallardo, A.: The religious problem in Spain. Washington, D.C. 1937. Tras la realización de este artículo ha sido publicado el $\mathrm{n}^{9} 13$ de la revista Ayer dedicado a la violencia. Igualmente, queda para otro trabajo mis investigaciones sobre la violencia en Colombia y Perú. 